\title{
Marital and Family Practices among Tribals of Himachal Pradesh
}

\author{
Raj Pathania, Praveen Kaur* and Pawan Pathania \\ Department of Human Development, College of Home Science, CSKHPKV, \\ Palampur 176 062, Himachal Pradesh, India \\ E-mail: dr_rajpathaniya@yahoo.com \\ *Department of Human Development and Family Studies, CCS Haryana Agricultural \\ University, Hisar 125 004, Haryana, India
}

KEYWORDS Ecology. Tribes. Family. Marriage. Polyandry

\begin{abstract}
The three tribal communities namely Gaddis, Kinnauras and Bhots of Himachal Pradesh were selected to study their existing marriage and family practices. The respondents were adolescents in the age group of 15-20 years. A total sample of 300 adolescents was selected. The study revealed that all the communities married their daughters between 19-21 years and sons were married later than 21 years. Majority of Bhots and Kinnauras reported non-existence of practices of matching horoscopes. Majority of Gaddis, half of Bhots and one third Kinnauras reported engagement ceremony. Majority of Bhots and Kinnauras and all Gaddis denied the prevalence of polyandry in their communities. Majority of Bhots and Kinnauras reported prevalence of endogamy. Divorce was allowed among Bhots and Kinnauras, whereas remarriage was allowed in all the three communities. Regarding settlement of family disputes, majority of the three communities reported it was the panchayat which helped in settling the family dispute. Vast majority of Bhots and Kinnauras and one third Gaddis reported that women were never beaten in the family. All the three communities denied the daughters getting share in the fathers' property. Majority of the respondents in the three communities reported both girls and boys were expected to take household responsibilities before 15 years of age.
\end{abstract}

\section{INTRODUCTION}

Himachal Pradesh has a number of tribal communities such as Kinnauras, Lahaulas, Pangwals, Swanglas, Khampas, Bhots/Bodhs, Jads, Lambs, Gujjars and Gaddis. They comprise four per cent of the total population of the state. In Himachal Pradesh, the Kinnaura is the single largest scheduled tribe which inhabits the district of Kinnaur. The tribal areas in the state are spread over the districts of Kinnaur, Lahaul and Spiti and Pangi and Bharmaur sub-divisions of Chamba district. Snow glaciers, high altitude and highly rugged terrain criss-crossed by fast flowing rivers and their tributaries are the peculiar features of the tribal belt.

For the present study, three tribal communities Kinnauras, Bhots and Gaddis were selected. In early literature, Kinnauras have often been associated with the Himalayas. In Meghadutam, the great poet Kalidasa sings of the majesty of their country and of the wives of Kinnaura singing in chorus of the victory over Tripura. It is believed that the present name, 'Kinnaur' is a corrupt form of the ancient 'Kinner'. Originally, the Kinner Desha of the Himalayas stretched from Kashmir to Nepal but now it has shrunk to modern Kinnaur in Himachal Pradesh. The
Kinners were the musicians in the court of God Indra.

The origins of Gaddis ascribes to immigration from the plains to the hilly areas to escape prosecution by the Muslim rulers and are descendants of the Khatris of Punjab. The role of tribal women (Gaddis and Gujjars) of Himachal Pradesh was studied by Shashi (1993). Gaddis, the semi-nomadic, semi-agricultural and pastoral tribe spent six months in search of fodder for their cattle and six months in their villages for sowing and harvesting their crops. The Gaddi woman had an equal status to that of a man.

The name Bodh has been derived from Tibetan region. Tibetans themselves call their country Bodyul. Bod is believed to be the name of their race. About Bhots, it seems that most of their ancestors came from Tibet and its surrounding countries. Many of those invaders settled down in these areas and mingled with the aborigines by marriage and other modes of social intercourse. These Tibetan infiltrations penetrated into the culture and religion of the aborigines with the result that many of the aborigines lost their distinct entity forever.

Each tribe has its own distinct characteristics, life patterns and styles indicating their cultural heritage. Practices related to marriage and 
family is tribe specific and distinct. The study of tribes manifests a rich variety. To understand the intricacies of tribal relation, a detailed study is needed. For this purpose, study on various aspects such as ecology, population, culture, customs, traditions, resources and status of development of tribals are essential (Tyagi and Banerjee 1994). Marriage is considered as a sacred contract in most religions confirmed by all the ceremonies and rituals accompanying it. It has been sanctified in several cultures as a spiritual and functional relationship between a man and a woman. There are various aspects related to marriage and family among tribals which need to be explored, so keeping this in mind, the present investigation was undertaken to study the existing tribal marriage and family practices.

\section{MATERIAL AND METHODS}

The State of Himachal Pradesh was selected purposively to study the tribal adolescents as the tribal population resides mainly in the three districts of Himachal Pradesh, namely Kinnaur, Lahaul and Spiti and Chamba districts. Moreover, there had been no such studies conducted in the study area to provide wider horizons to the area of research.

The sample consisted of adolescents in the age range of 15-20 years. The data were selected from the three districts based on the density of population, thereby, the total sample was 300 of which 150 were males and 150 were females. The sample was selected randomly from various pockets of the tribal districts. The three main communities representing the tribal districts namely Gaddis (Bharmaur subdivision of Chamba district), Kinnauras (Kinnaur district) and Bhots (Lahaul and Spiti district) were selected for the present study.

\section{RESULTS AND DISCUSSION}

\section{Marital Practices}

Marriage is considered as a sacred contract in most religions confirmed by all the ceremonies and rituals accompanying it. It has been sanctified in several cultures as a spiritual and functional relationship between a man and a woman. There are various aspects related to marriage and family among tribals that need to be explored.
Marriage Age for Boys and Girls: As per the legal provision the age at marriage for boys is 21 years and 18 years for girls. Table 1 show that the general trend in the girl's marriage age it was 19-21 years as has been reported by majority of Gaddis (95\%) followed by 79.23 per cent Kinnauras and Bhots $(72.86 \%)$. Sometimes it was 16-18 years also as witnessed by 18.57 per cent Bhots, Kinnauras (19.23\%) and least by $4 \%$ Gaddis. Marriage age for boys in the tribal community as reported by 11.43 per cent Bhots and 6.15 per cent Kinnauras as less than 19 years. Majority of the Bhots $(81.43 \%)$ and Kinnauras $(86.92 \%)$ had practices of marrying the boys at the age of later than 21 years. All the Gaddis married their boys after attaining 21 years of age. In this regard Bhasin (1990) reported that age at marriage among Gaddi Brahamans was slightly lower (17.8 years) than among the Rajputs and Scheduled castes (18.3 and 18.4 years, respectively). The main reason for the child marriages of females or the early marriage as reported by Jain (1990) was to a large extent the prejudice against girls arise from the fear over their security right from time they were born all through their womanhood.

Similar findings are reported by Singh (2001) who observed that no girl could marry before she was 20 years of age and no boys before 25 years of age among the Santals of Bihar.

Contrary to the present study, Pandey (2001) reported marriage of girls at a very young age (12-14 years) was the main reason for the high rate of dropouts among girls.

Matching Horoscope: The results show that vast majority of Bhots $(95.71 \%)$ and Kinnauras $(90 \%)$ and only 29 per cent Gaddis reported nonexistence of practice of matching horoscope in their community whereas majority of Gaddis (71\%) and only 4-10 per cent Bhots and Kinnauras reported that horoscopes were matched during marriage in their community.

Engagement Ceremony: When parents of the boy and the girl agree for marital contract, the engagement ceremony takes place. The results in Table 1 show that vast majority of Gaddis (95\%), half of Bhots $(54.28 \%)$ and onethird Kinnauras $(34.62 \%)$ reported that engagement ceremony took place in their community whereas less than half Bhots (45.71\%) and 65.38 per cent Kinnauras and only 6 per cent Gaddis gave negative response i.e. indicating no specific highlighted engagement ceremonies. 
Table 1: Existing marriage practices in tribal communities

\begin{tabular}{|c|c|c|c|c|c|c|}
\hline $\begin{array}{l}\text { S. } \\
\text { No. }\end{array}$ & Variable & Categories & $\begin{array}{l}\text { Gaddis } \\
(n=100)\end{array}$ & $\begin{array}{l}\text { Kinnauras } \\
(n=130)\end{array}$ & $\begin{array}{l}\text { Bhots } \\
(n=70)\end{array}$ & $\begin{array}{l}\text { Total } \\
(N=300)\end{array}$ \\
\hline \multirow[t]{4}{*}{1.} & \multirow[t]{4}{*}{ Marriage age for girls } & $<15$ yrs & $0(0.00)$ & $1(0.77)$ & $1(1.43)$ & $2(0.67)$ \\
\hline & & $16-18 \mathrm{yrs}$ & $4(4.00)$ & $25(19.23)$ & $13(18.57)$ & $42(14.00)$ \\
\hline & & $19-21 \mathrm{yrs}$ & $95(95.00)$ & $103(79.23)$ & $51(72.86)$ & $249(83.00)$ \\
\hline & & Above 21 yrs & $1(1.00)$ & $1(0.77)$ & $5(7.14)$ & $7(2.33)$ \\
\hline \multirow[t]{4}{*}{2.} & \multirow[t]{4}{*}{ Marriage age for boys } & $<15 \mathrm{yrs}$ & $0(0.00)$ & $3(2.31)$ & $0(0.00)$ & $3(1.00)$ \\
\hline & & $16-18 \mathrm{yrs}$ & $0(0.00)$ & $8(6.15)$ & $8(11.43)$ & $16(5.33)$ \\
\hline & & $19-21$ yrs & $1(1.00)$ & $6(4.62)$ & $5(7.14)$ & $12(4.00)$ \\
\hline & & Above 21 yrs & $99(99.00)$ & $113(86.92)$ & $57(81.43)$ & $269(89.67)$ \\
\hline \multirow[t]{2}{*}{3.} & \multirow[t]{2}{*}{ Horoscopes } & Matching & $71(71.00)$ & $13(10.00)$ & $3(4.29)$ & $87(29.00)$ \\
\hline & & Not matching & $29(29.00)$ & $117(90.00)$ & $67(95.71)$ & $213(71.00)$ \\
\hline \multirow[t]{2}{*}{4.} & \multirow[t]{2}{*}{ Engagement ceremony } & Celebrate & $94(94.00)$ & $45(34.62)$ & $38(54.28)$ & $177(59.00)$ \\
\hline & & Do not celebrate & $6(6.00)$ & $85(65.38)$ & $32(45.71)$ & $123(41.00)$ \\
\hline \multirow[t]{2}{*}{5.} & \multirow[t]{2}{*}{ Celebrations } & Traditional way & $99(99.00)$ & $124(95.38)$ & $68(81.14)$ & $291(97.00)$ \\
\hline & & Modern way & $1(1.00)$ & $6(4.62)$ & $2(2.86)$ & $9(3.00)$ \\
\hline \multirow[t]{2}{*}{6.} & \multirow[t]{2}{*}{ Polyandry } & Follow & $0(0.00)$ & $32(24.62)$ & $18(25.71)$ & $50(16.67)$ \\
\hline & & Do not follow & $0(100.00)$ & $98(75.38)$ & $52(74.29)$ & $250(83.33)$ \\
\hline \multirow[t]{2}{*}{7.} & \multirow[t]{2}{*}{ Endogamy } & Follow & $4(4.00)$ & $90(69.23)$ & $52(74.29)$ & $146(48.67)$ \\
\hline & & Do not follow & $96(96.00)$ & $40(30.77)$ & $18(25.71)$ & $154(51.33)$ \\
\hline \multirow[t]{2}{*}{8.} & \multirow[t]{2}{*}{ Divorce } & Allowed & $37(37.00)$ & $114(87.69)$ & $57(81.43)$ & $208(69.33)$ \\
\hline & & Not allowed & $63(63.00)$ & $16(12.31)$ & $13(18.57)$ & $92(30.67)$ \\
\hline \multirow[t]{2}{*}{9.} & \multirow[t]{2}{*}{ Remarriage } & Allowed & $63(63.00)$ & $103(79.23)$ & $62(88.57)$ & $228(76.00)$ \\
\hline & & Not allowed & $37(37.00)$ & $27(20.77)$ & $8(11.43)$ & $72(24.00)$ \\
\hline
\end{tabular}

Figures in parentheses indicate percentage

Common Place for Marriage: There were two types of places where marriages took place. One was the traditional in which place of marriage was home, temple and monastery whereas non-traditional place of marriage were hotel or marriage palaces.

Results exhibit that vast majority of the respondents of three communities reported that marriage took place in the home, only 1-4 per cent respondents of the three communities reported non-traditional place for marriage ceremony.

Polyandry: It is a form of union in which a woman has more than one husband at a time or in which brothers share a wife and have wives in common. In such cases the family house belongs to the eldest brother, the property, wife and children are owned by him. At present in India, some tribes still favour polyandry to any other type of marriage. They worship the Pandvas and Droupadi as their deities.

Table 1 further shows that majority of the respondents 74-75 per cent Bhots and Kinnauras and all Gaddis (100\%) denied the prevalence of polyandry in their community whereas $24-25$ per cent Bhots and Kinnauras reported in affirmative. This shows that multi-marriages were still continuing in these tribal communities. Though they were gradually shifting to monogamy. The study finds support from Samal et al. (1996) and
Chantia (2004) who observed the Jaunsari tribe of Dehradun once mostly adhered to polyandry was now shifting to monogamy. Contrary to this, Oberoi (1985) reported monogamy was common among Pangwal tribe of Himachal Pradesh.

Endogamy: Families are classified according to marriage regulations and forms. Endogamous rule which prescribes that an individual must choose a mate within a certain group of which he is a member. Regarding Himachal Pradesh tribes it is allowed in some and not in others. Perusal of Table 1 shows that endogamous marriages were prevalent and reported by three-fourth Bhots (74.29\%), 69.23 per cent Kinnauras and only by 4 per cent Gaddis whereas vast majority of Gaddis (96\%) and only 25-30 per cent Bhots and Kinnauras reported negative responses.

Similar findings were reported by Debbarman (1991) and Mutharayappa (1994) who observed elopement marriage and marriage within consanguineous group among the tribals. Whereas, the findings reported by Babu and Naidu (1994) were opposite to the present findings.

Divorce: It is an official recognition that their marriage is a failure and therefore has more cause for being terminated rather than continuing. However, though divorce indicates the failure of a particular marriage, its absence does not indicate success. 
Table 1 points out that majority of respondents, 81 per cent Bhots and 88 per cent Kinnauras and only 37 per cent Gaddis reported that divorce was allowed in their community and whereas good number of Gaddis (63\%) and only 12-18 per cent Bhots and Kinnauras denied this. Oberoi (1985) reported that divorce was allowed among all Pangwal tribe residing in the Pangi area of Himachal Pradesh.

Remarriage: Remarriage often follows the death of wife or husband and this leads to disorganization and disruption in the structure and functions of the family and this brings crisis in the family.

Perusal of Table 1 shows remarriage was allowed in three communities reported by $79-88$ per cent Bhots, Kinnauras and 63 per cent Gaddis. One-third Gaddis (37\%) and only 11-20 per cent each in case of Bhot and Kinnaura communities reported negative response to this statement. Contrary to the present findings, Pirabu et al. (1998) reported that widow remarriage was restricted among the tribals of Tamil Nadu.

\section{Family Practices}

Human needs bring about creative changes and the needs themselves are changing from time to time. When the individual members change the family has to respond and resulting in community also changes. The tribal communities are also in the process of transition and so are the changes in the family system of the tribals.

Settlement of Marital Disputes: Change brings with it the inevitable necessity for making adjustments. Many changes begin with small situation that may appear trifling in the earlier days but become crisis because of their persistence and upsetting influence on the emotional stability of the individual who has to meet the problem. A crisis is something that makes one strive for a different and unusual solution of the problem.

Table 2 unveils that majority of Gaddi (81\%) only 19-27 per cent Bhots and Kinnauras reported that couples carry on with the marriage crisis. Half of the Kinnauras (50.77\%) and one-fourth Bhots $(25.71 \%)$ and only one-tenth Gaddis (10\%) reported couples seeking divorce. Nearly onethird Bhots and 6-14 per cent Gaddis and Kinnauras reported separation. Similar percentage of Bhots and Kinnauras (15\%) and only 3 per cent Gaddis reported remarriage among their communities.

Settlement of Family Disputes: Any disorganization and disruption in the structure and functions of the family needs immediate attention of the family members. This is based on the theory of 'Nip the evil in the bud'. Otherwise it

Table 2: Existing family practices in tribal communities

\begin{tabular}{|c|c|c|c|c|c|c|}
\hline $\begin{array}{l}\text { S. } \\
\text { No. }\end{array}$ & Variable & Categories & $\begin{array}{l}\text { Gaddis } \\
(n=100)\end{array}$ & $\begin{array}{l}\text { Kinnauras } \\
(n=130)\end{array}$ & $\begin{array}{l}\text { Bhots } \\
(n=70)\end{array}$ & $\begin{array}{l}\text { Total } \\
(N=300)\end{array}$ \\
\hline \multirow[t]{4}{*}{1.} & \multirow[t]{4}{*}{$\begin{array}{l}\text { Action when marriage } \\
\text { in trouble }\end{array}$} & $\begin{array}{l}\text { Carry on } \\
\text { with marriage }\end{array}$ & $81(81.00)$ & $25(19.23)$ & $19(27.14)$ & $125(41.67)$ \\
\hline & & Seek divorce & $10(10.00)$ & $66(50.77)$ & $18(25.71)$ & $94(31.33)$ \\
\hline & & Separation & $6(6.00)$ & $19(14.62)$ & $22(31.43)$ & $47(15.67)$ \\
\hline & & Remarriage & $3(3.00)$ & $20(15.38)$ & $11(15.71)$ & $34(11.33)$ \\
\hline \multirow[t]{3}{*}{2.} & \multirow[t]{3}{*}{$\begin{array}{l}\text { Settlement of family } \\
\text { disputes by }\end{array}$} & $\begin{array}{l}\text { Elderly people } \\
\text { of community }\end{array}$ & $94(94.00)$ & $76(58.46)$ & $48(68.57)$ & $218(72.67)$ \\
\hline & & Panchayat & $6(6.00)$ & $54(41.54)$ & $11(15.71)$ & $71(23.67)$ \\
\hline & & By self & $0(0.00)$ & $0(0.00)$ & $11(15.71)$ & $11(3.67)$ \\
\hline \multirow[t]{5}{*}{3.} & \multirow[t]{5}{*}{$\begin{array}{l}\text { Domestic violence of } \\
\text { women in the family by }\end{array}$} & Mother-in-law & $38(38.00)$ & $2(1.54)$ & $2(2.86)$ & $42(14.00)$ \\
\hline & & Sister-in-law & $0(0.00)$ & $0(0.00)$ & $0(0.00)$ & - \\
\hline & & Husband & $30(30.00)$ & $7(5.38)$ & $0(0.00)$ & $37(12.33)$ \\
\hline & & Brother-in-law & $0(0.00)$ & $0(0.00)$ & $0(0.00)$ & - \\
\hline & & None & $32(32.00)$ & $121(93.08)$ & $68(97.14)$ & $221(73.67)$ \\
\hline \multirow[t]{2}{*}{4.} & \multirow{2}{*}{$\begin{array}{l}\text { Property allocation - } \\
\text { share in father's property }\end{array}$} & Daughters & $0(0.00)$ & $1(0.77)$ & $3(4.29)$ & $4(1.33)$ \\
\hline & & Sons & $100(100.00)$ & $129(99.23)$ & $67(95.71)$ & $296(98.67)$ \\
\hline \multirow[t]{6}{*}{5.} & \multicolumn{6}{|l|}{ Transformation age } \\
\hline & a) Girls taking & $<15 \mathrm{yrs}$ & $81(81.00)$ & $124(95.38)$ & $62(88.57)$ & $267(89.00)$ \\
\hline & responsibilities at & $>15 \mathrm{yrs}$ & $19(19.00)$ & $6(4.62)$ & $8(11.43)$ & $33(11.00)$ \\
\hline & \multirow{3}{*}{$\begin{array}{l}\text { b) Boys taking } \\
\text { responsibilities at }\end{array}$} & $<15$ yrs & $75(75.00)$ & $122(93.85)$ & $57(81.43)$ & $254(84.67)$ \\
\hline & & $16-18$ yrs & $25(25.00)$ & $6(4.62)$ & $9(12.86)$ & $40(13.33)$ \\
\hline & & $19-21$ yrs & $0(0.00)$ & $2(1.54)$ & $4(5.71)$ & $6(2.00)$ \\
\hline
\end{tabular}

Figures in parentheses indicate percentage 
may lead to threat to the family unity. Every family and the community have its own set of rules and regulations for the members. Tribals have their own culture that is carried over like heirloom to the next generation.

Table 2 shows that family disputes were settled by elderly people of the community as reported by vast majority of Gaddis (94\%) and 58 per cent and 68 per cent Kinnauras and Bhots respectively. Panchayats were also involved in the settlement of family disputes among 41.54 per cent Kinnauras, 15.71 per cent Bhots and only 6 per cent Gaddis. Only 15.71 per cent Bhots reported settlement of family disputes by themselves. This shows the communities played important role in sustaining the family by settling and solving the disputes.

Domestic Violence: The tribal women have been empowered with the civic rights of the country. But the custom of their own community stand in their way to enjoy the fruits of the law and thus come into conflict with civic rules and norms of wider society.

Table 2 further enlists that vast majority of Bhots $(97.14 \%)$ and 93.08 per cent Kinnauras and only one-third of Gaddi communities reported that women were never beaten in the family. Whereas, from husbands, 30 per cent Gaddis and only 5.38 per cent Kinnauras and none among Bhots were reported beating the wife. One-third Gaddis (38\%) and 1-2 per cent Bhots and Kinnauras reported mothers-in-law beating the daughter-in-law. This violence might be the cause of disputes. The punitive practice might be a form of teaching the young girls who had to learn a lot of new things in the new home of inlaws. Since they were married at young age, there might be conflicts in roles expected from them and the roles enacted by them.

Similar findings were found by Unnithan (1991) among Girasia tribe where women within the tribe were more powerful than their other caste counterparts.

Daughter's Share in Father's Property: Legal provision in the constitution indicate that daughters are also entitled to have equal share in father's property as that of sons. The tribals' practice of property distribution is clear from Table 2. Vast majority of two communities and cent per cent Gaddis denied daughters getting share in father's property whereas only 4.29 per cent Bhots and negligible $(0.77 \%)$ Kinnauras reported it in practice. There was general trend of matrilineal system and property passes on to sons.
The study finds support from Debbarman (1991) who reported the land property was transmitted from fathers to sons among Santals of Bihar.

Transformation Age: The son preference is universal all over the world with few exceptions and variations. When we look at the tribals' present scenario, the difference is not seen among the males and females about the age at which girls and boys expected to take up the household responsibilities. Table 2 further shows majority of the respondents in three communities reported girls were expected to take household responsibility at less than 15 years of age. Boys were also expected to take household responsibilities at less than 15 years as reported by majority of respondents of the three communities (75-94\%). In some cases, it was in the age between 16-18 years for boys leaving room for individual variations.

\section{CONCLUSION}

To conclude, the tribals are in the phase of transition and are changing themselves as well as their practices related to marriage and family. They have lived in isolation for centuries together in the hills and forests and lived away from the mainstream. Although the progress has been taking place in their attitudes and practices due to education, awareness, interventions by Government and NGOs and many other factors, but still a lot to be done.

\section{REFERENCES}

Babu BV, Naidu JM 1994. Marriage pattern and distance among the two subtribes of Mali of Andhra Pradesh. South Asia Anthropologist, 15(1-2): 5153.

Bhasin Veena 1990. Habitats, Habitationa and Health in Himalayas. Delhi, Kamla Raj Enterprises, pp. 184-185

Chantia Alok 2004. Problems of Jaunsari women. An appraisal. Proceedings of the $91^{\text {st }}$ Session of the Indian Science Congress, held at Chandigarh in Jan. 3-7.

Debbarman Prasenjit 1991. Tribal society in India: A study of Santhals. Folklore, 32(3): 82-85.

Jain R 1990. The stigma of being born as a girl. Social Welfare, 36(10-11): 21-23.

Mutharayappa R 1994. Factors affecting fertility among tribal. Man and Dev, 16(4): 63-78.

Oberoi RC 1985. Constraints in Agricultural Development with Special Reference to Pangi Tehsil in Chamba District. Ph.D. Thesis (Unpublished). Himachal Pradesh Krishi Vishvavidyalaya, Palampur. 
Pandey Alok 2001. Kols of Uttar Pradesh: Struggling for survival. Man and Dev, 23(1): 20-26.

Pirabu Venkata J, G Perumal G, Palaniswamy S 1998. Leaders/Social control over the society in tribal and progressive villages. $J$ Ext Edu, 9(4): 2259-2260.

Samal PK, Chauhan MS, Fernando R 1996. The functioning and eco-cultural significance of marriage type among the Jaunsaries in central Himalayas. Man in India, 76(3):199-214.

Shashi SS 1993. The nomadic women of Himalayas:
With reference to the girl child. J Edu Social Change, 6(4): 61-68.

Singh Uday Narayan 2001. Changing profile of Santals in Bihar. Man and Dev, 23(1): 12-19.

Tyagi D, Banerjee M 1994. The North East: Anthropological Perspectives. IASSI Quarterly, 12(3\&4): 44-48.

Unnithan Kumar M 1991. Gender and tribal identity in Western India. Economic and Politial Weekly, 26(17): 36-39. 